University of Wollongong

Research Online

Australian Institute for Innovative Materials -

Papers

Australian Institute for Innovative Materials

$1-1-2019$

Electrostatically assembled construction of ternary TiO2-Cu@C hybrid with enhanced solar-to-hydrogen evolution employing amorphous carbon dots as electronic mediator

Jiaxin Zhu

Wuhan Institute of Technology

Mengmeng Zhang

Wuhan Institute of Technology

Jinyan Xiong

Wuhan Textile University, jx513@uowmail.edu.au

Yinan Yan

National Engineering Research Center for Nanotechnology

Weijie Li

University of Wollongong,weijie@uow.edu.au

See next page for additional authors

Follow this and additional works at: https://ro.uow.edu.au/aiimpapers

Part of the Engineering Commons, and the Physical Sciences and Mathematics Commons

Research Online is the open access institutional repository for the University of Wollongong. For further information contact the UOW Library: research-pubs@uow.edu.au 


\title{
Electrostatically assembled construction of ternary TiO2-Cu@C hybrid with enhanced solar-to-hydrogen evolution employing amorphous carbon dots as electronic mediator
}

\begin{abstract}
The huge demand for renewable hydrogen produced by water splitting has prompted people to conduct in-depth research on the hydrogen evolution reaction for the development of earth-abundant, nonprecious, and multi-functional metal catalysts. Herein, a noble-metal-free ternary composite of TiO2-Cu@C was prepared by electrostatic self-assembly loaded copper nanoparticles and amorphous carbon dots (CDs) on porous $\mathrm{TiO} 2$ microrods. The good conductivity of the CDs was beneficial to promoting the charge transfer and separation, generating an enhanced solar-to-hydrogen performance on TiO2-Cu@C. The optimized TiO2-Cu@C reveals a stable and notable hydrogen evolution rate of 3911 $\mu \mathrm{mol} \mathrm{g}-1 \mathrm{~h}-1$, which is 1.6 times that of TiO2-Cu and many times higher than that of TiO2. Instead of providing active sites for hydrogen production, the CDs act as an electronic mediator and provide another electron pathway to further enhance the activity of $\mathrm{TiO} 2-\mathrm{Cu}$, where the photogenerated electrons on $\mathrm{TiO} 2$ could pass through the CDs to the copper cocatalyst and reduce water to hydrogen.
\end{abstract}

\section{Keywords}

electrostatically, assembled, construction, ternary, tio2-cu@c, hybrid, electronic, enhanced, mediator, solar-to-hydrogen, evolution, employing, amorphous, carbon, dots

Disciplines

Engineering | Physical Sciences and Mathematics

\section{Publication Details}

Zhu, J., Zhang, M., Xiong, J., Yan, Y., Li, W. \& Cheng, G. (2019). Electrostatically assembled construction of ternary TiO2-Cu@C hybrid with enhanced solar-to-hydrogen evolution employing amorphous carbon dots as electronic mediator. Chemical Engineering Journal, 375 121902-1-121902-7.

\section{Authors}

Jiaxin Zhu, Mengmeng Zhang, Jinyan Xiong, Yinan Yan, Weijie Li, and Gang Cheng 


\section{Electrostatically assembled construction of ternary $\mathrm{TiO}_{2}-\mathrm{Cu} @ \mathrm{C}$}

\section{hybrid with enhanced solar-to-hydrogen evolution employing}

\section{amorphous carbon dots as electronic mediator}

Jiaxin Zhu a, Mengmeng Zhang a, Jinyan Xiong b,*, Yinan Yan c, Weijie Li d, Gang Cheng a,*

a School of Chemistry and Environmental Engineering, Wuhan Institute of Technology, Xiongchu Avenue, Wuhan 430073, PR China.

E-mail: gchenglab@163.com (G. Cheng)

${ }^{b}$ College of Chemistry and Chemical Engineering, Wuhan Textile University, Wuhan 430200, Hubei,

China.

E-mail: jx513@uowmail.edu.au (J. Xiong)

c National Engineering Research Center for Nanotechnology, Shanghai, P. R. China

${ }^{d}$ Institute for Superconducting and Electronic Materials, University of Wollongong, Innovation Campus, Squires Way, North Wollongong, NSW 2500, Australia

\# The details of experiments are provided in the Supporting Information.

* Authors to whom correspondence should be addressed. 


\section{Abstract}

The huge demand for renewable hydrogen produced by water splitting has prompted people to conduct in-depth research on the hydrogen evolution reaction for the development of earth-abundant, non-precious, and multi-functional metal catalysts. Herein, a noble-metal-free ternary composite of $\mathrm{TiO}_{2}-\mathrm{Cu} @ \mathrm{C}$ was prepared by electrostatic self-assembly loaded copper nanoparticles and amorphous carbon dots (CDs) on porous $\mathrm{TiO}_{2}$ microrods. The good conductivity of the $\mathrm{CDs}$ was beneficial to promoting the charge transfer and separation, generating an enhanced solar-to-hydrogen performance on $\mathrm{TiO}_{2}-\mathrm{Cu} @ \mathrm{C}$. The optimized $\mathrm{TiO}_{2}-\mathrm{Cu} @ \mathrm{C}$ reveals a stable and notable hydrogen evolution rate of 3911 $\mu \mathrm{mol} \mathrm{h} \mathrm{h}^{-1}$, which is 1.6 times that of $\mathrm{TiO}_{2}-\mathrm{Cu}$ and many times higher than that of $\mathrm{TiO}_{2}$. Instead of providing active sites for hydrogen production, the CDs act as an electronic mediator and provide another electron pathway to further enhance the activity of $\mathrm{TiO}_{2}-\mathrm{Cu}$, where the photogenerated electrons on $\mathrm{TiO}_{2}$ could pass through the $\mathrm{CDs}$ to the copper cocatalyst and reduce water to hydrogen.

\section{Keywords}

$\mathrm{TiO}_{2}-\mathrm{Cu} @ \mathrm{C}$ hybrids; photocatalytic water splitting; electrostatical assemble; carbon dots

\section{Introduction}

Hydrogen $\left(\mathrm{H}_{2}\right)$ is a clean energy source, which does not produce other exhaust gases in combustion except for water. It can play an important role in replacing fossil fuels, further solving environmental problems and the energy crisis. At present, using semiconductor-based photocatalysis technology to covert solar energy into hydrogen is being considered as a potential approach to dealing with these issues. In the most recent progress on photocatalytic systems, the construction of heterojunctions has become a research hotspot because of its feasibility and effectiveness for space separation of 
photogenerated electron-hole pairs. The research on $\mathrm{TiO}_{2}$ used alone has made some progress, but its activity towards water-splitting is still limited. [1-4] Because of its own characteristics, photogenerated electron-hole pairs recombine rapidly, and it has a wide band gap and fewer active sites just like ZnO $[5,6]$. Yet the $\mathrm{TiO}_{2}$-based photocatalytic system for water splitting is also progressing. [7-12] For example, conventional type II heterojunctions of $\mathrm{TiO}_{2}, \mathrm{TiO}_{2} p-n$ heterojunctions, $\mathrm{TiO}_{2} / \mathrm{metal}$ heterojunctions, and $\mathrm{TiO}_{2}$-based $\mathrm{Z}$-scheme heterojunctions have been constructed to greatly enhance its photocatalytic activity towards hydrogen production, although there are few studies on further improvement of the activity of binary complexes through rational surface/interface engineering.

Cost-effective metallic $\mathrm{Cu}$ has recently been recognized as a good substitute for precious metals in hydrogen production. [13-18] It was found that metallic Cu has moderate catalytic activity towards hydrogen evolution compared with noble metals according to theoretical studies. [19] When metallic $\mathrm{Cu}$ acts as a cocatalyst can optimize the free energy of hydrogen adsorption and improve the catalytic activity of hydrogen production, just like some non-precious electrocatalysts [20, 21]. Moreover, metallic Cu with a specific size and morphology exhibits surface plasmon resonance (SPR) effects similar to those of noble metals. [22-24] Metallic Cu as a cocatalyst, however, has only a single electron transfer path with the semiconductor, and it is likely to be oxidized in the course of a long-term catalytic process because of its direct contact with the semiconductor surface. This limits the photocatalytic activity of binary Cu-based photocatalysts, which needs further improvement.

Carbon dots, as a novel class of nanocarbons, have been widely used in the field of photocatalysis due to their excellent photoelectric properties. [25-29] Zhang et al. applied the electron reservoir characteristic of CDs to capture the electrons generated by metallic $\mathrm{Cu}$ nanoparticles, thus hindering electron-hole recombination to improve photocatalytic activity. [26] According to Zhang et al., CDs play 
a dual role in improving photocatalytic activity, as photosensitizer and as electron reservoir. [27] In Bian's group, coupling $\mathrm{CDs}$ with $\mathrm{TiO}_{2}$, in which $\mathrm{CDs}$ acted as electron collectors and active sites, makes the activity towards reducing $\mathrm{Cr}(\mathrm{VI})$ to $\mathrm{Cr}(\mathrm{III})$ about 5.4 times higher than that of pure $\mathrm{TiO}_{2}$. [28] Owing to the high conductivity of CDs [30], they could capture photogenerated electrons from the conduction band of semiconductors, so decorating CDs on the binary materials would provide other multi-step electron transfer pathways and possibly inhibit the photocorrosion of the photocatalyst.

In this work, we present a reasonably designed method that operates through a hierarchical electrostatic assembly method to fabricate ternary $\mathrm{TiO}_{2}-\mathrm{Cu} @ \mathrm{C}$ composites. The amorphous carbon dots were dispersed on the $\mathrm{TiO}_{2}-\mathrm{Cu}$ to synthesize $\mathrm{TiO}_{2}-\mathrm{Cu} @ \mathrm{C}$ nanocomposites without noble metals, resulting in efficient photocatalytic water splitting. The $\mathrm{H}_{2}$ evolution rate on $\mathrm{TiO}_{2}-\mathrm{Cu} @ \mathrm{C}$ was further enhanced by about 1.6 times over that of the $\mathrm{TiO}_{2}-\mathrm{Cu}$ binary compound. The improved charge separation was possibly due to the formation of carbon- $\mathrm{Cu}$ and carbon- $\mathrm{TiO}_{2}$ interfaces, which creates another type of electron transfer pathway: electrons pass through the $\mathrm{CDs}$ on $\mathrm{TiO}_{2}$ to metallic $\mathrm{Cu}$ to reduce water, beyond the direct electrons transfer from $\mathrm{TiO}_{2}$ to metallic $\mathrm{Cu}$. This may be the origin of the enhancement of photocatalytic activity of $\mathrm{TiO}_{2}-\mathrm{Cu} @ \mathrm{C}$.

\section{Results and discussion}

To better understand the electrostatic assemble method for the synthesis of ternary $\mathrm{TiO}_{2}-\mathrm{Cu} @ \mathrm{C}$ composites, the surface charges of the related materials estimated by zeta-potential measure were depicted in Figure 1. It can be observed that the materials of $\mathrm{TiO}_{2}, \mathrm{Cu}$, Carbon dots, and $\mathrm{TiO}_{2}-\mathrm{Cu}$ had different zeta potential. 


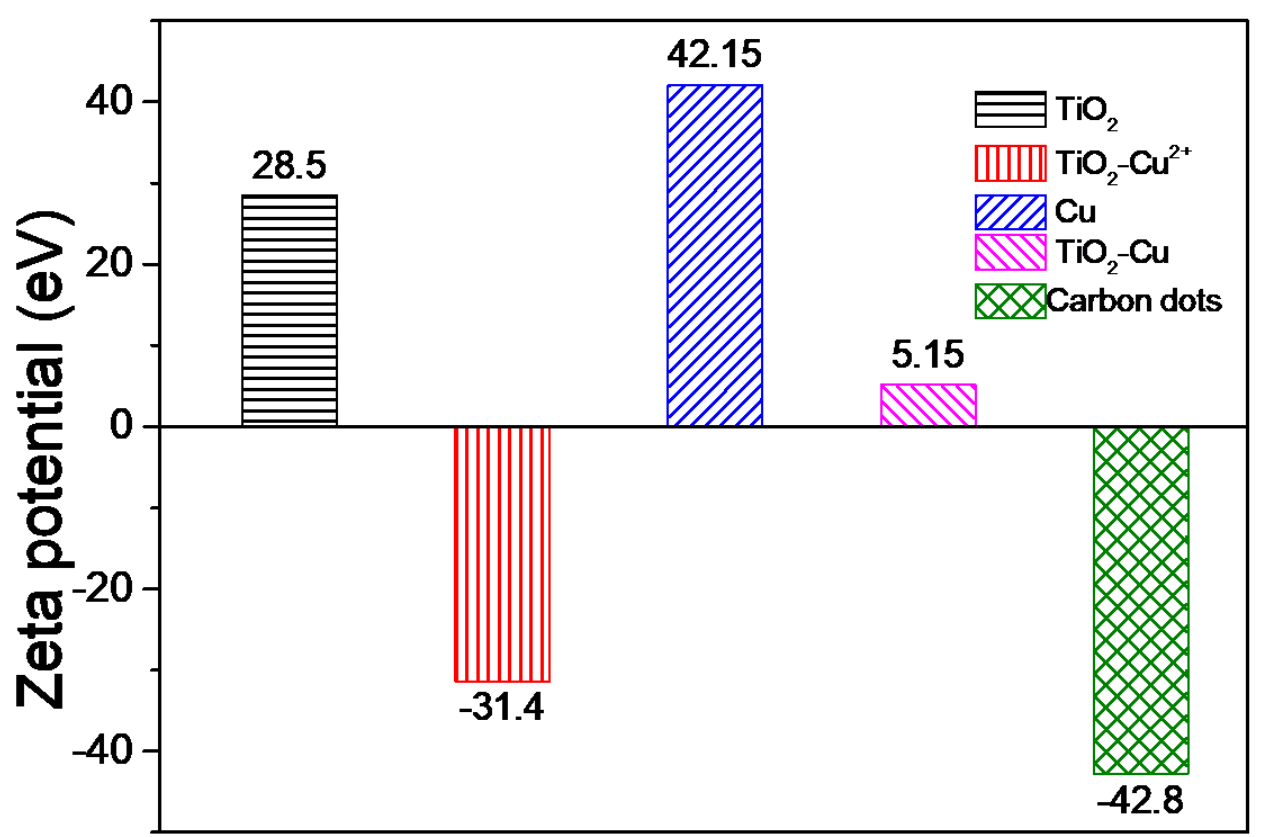

Figure 1 Zeta potentials of mesoporous $\mathrm{TiO}_{2}$ microrods $\left(\mathrm{m}-\mathrm{TiO}_{2}\right), \mathrm{TiO}_{2}-\mathrm{Cu}^{2+}$ precursor, metallic $\mathrm{Cu}, \mathrm{TiO}_{2}-\mathrm{Cu}$, and carbon dots (average results of three tests)

The synthesis strategy and formation process of $\mathrm{TiO}_{2}-\mathrm{Cu} @ \mathrm{C}$ are shown in Figure 2, in which surface charges play an important role in such a preparation approach. Firstly, negatively charged porous $\mathrm{TiO}_{2}$ $(\zeta=28.5 \mathrm{mV})$ adsorbed positively charged $\mathrm{Cu}^{2+}$-precursor to form the $\mathrm{TiO}_{2}-\mathrm{Cu}^{2+}$-precursor $(\zeta=-31.4 \mathrm{mV})$. Afterwards, the $\mathrm{TiO}_{2}-\mathrm{Cu}^{2+}$-precursor was reduced to a $\mathrm{TiO}_{2}-\mathrm{Cu}(\zeta=5.15 \mathrm{mV})$ hybrid that was positively charged on its surface. When the carbon dots solution was added to the $\mathrm{TiO}_{2}-\mathrm{Cu}$, the negatively charged carbon dots $(\zeta=-42.8 \mathrm{mV})$ would be electrostatically attracted and loaded on $\mathrm{TiO}_{2}-\mathrm{Cu}$ to form the $\mathrm{TiO}_{2}-$ Cu@C ternary composite. Due to the effect of electrostatic attraction, the strong connection existing among the $\mathrm{TiO}_{2}$, metallic $\mathrm{Cu}$, and carbon dots could make the modified nanoparticles disperse uniformly. 


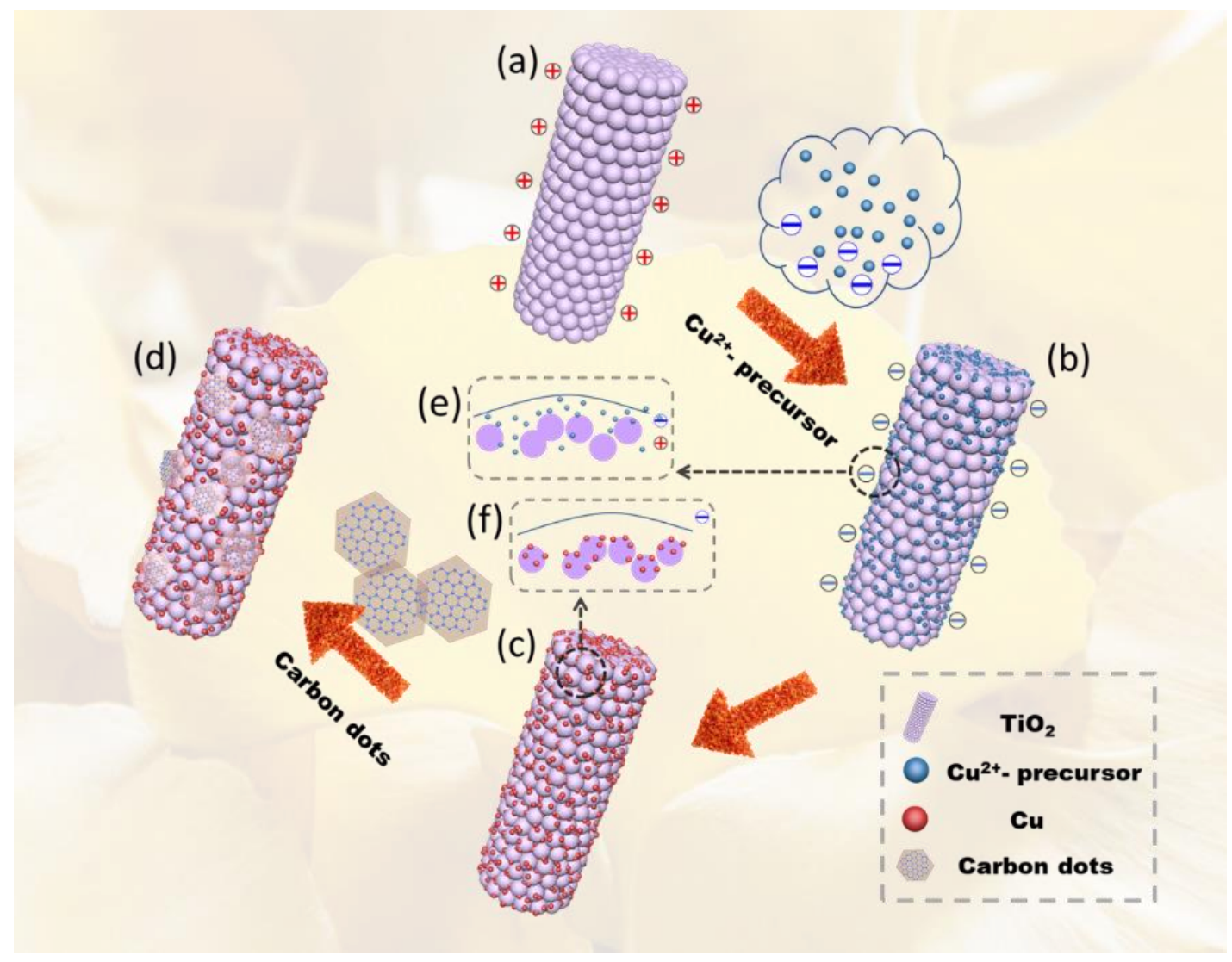

Figure 2. Schematic illustration of the multi-step positive-negative-negative electrostatic assembly synthesis of $\mathrm{TiO}_{2}$-Cu@C. (a) mesoporous $\mathrm{TiO}_{2}$ microrods $\left(\mathrm{m}-\mathrm{TiO}_{2}\right)$ with positively charged surface in aqueous solution; (b) formation of an electron-bi-layer after absorption of $\left[\mathrm{CuL}_{2}(\mathrm{OH})\right]^{3-}$ precursor onto $\mathrm{m}-\mathrm{TiO}_{2} ;$ (c) formation of $\mathrm{TiO}_{2}$ $\mathrm{Cu}$ composite with negatively charged surface in aqueous solution; (d) prepared ternary $\mathrm{TiO}_{2}$ - $\mathrm{Cu} @ \mathrm{C}$ hybrid through mixing $\mathrm{TiO}_{2}-\mathrm{Cu}$ composite with carbon dot solution under stirring at room temperature.

The crystal structure and morphology of the $\mathrm{TiO}_{2}-\mathrm{Cu} @ \mathrm{C}$ hybrid were characterized by X-ray diffraction (XRD) (Figure 3a-b), X-ray photoelectron spectroscopy (XPS) (Figure S1), scanning electron microscopy (SEM) (Figure 3d, Figure S2), transmission electron microscopy (TEM) (Figure 3e), and high resolution TEM (HRTEM) (Figure 3f). As shown in Figure 3a, most of the X-ray diffraction peaks of the products correspond to anatase $\mathrm{TiO}_{2}$ (JCPDS card No. 73-1764). The characteristic diffraction peak at $2 \theta=43.3^{\circ}$ that is indexed to the (111) planes of metallic copper (JCPDS card No. 70-3039) was clearly observed 
(Figure 3b). In addition, Fourier transform infrared spectroscopy (FT-IR) characterization was performed to further confirm that $\mathrm{CDs}$ were attached on the $\mathrm{TiO}_{2}-\mathrm{Cu}$ composite (Figure 3c). The characteristic absorption peaks of the CDs could be detected at 2980,1568 , and $1402 \mathrm{~cm}^{-1}$, which are attributed to the skeleton vibrations of $s p^{2} \mathrm{C}-\mathrm{H}, \mathrm{C}=\mathrm{O}$, and $\mathrm{C}-\mathrm{OH},[27]$ implying the existence of $\mathrm{CDs}$ in the $\mathrm{TiO}_{2}-\mathrm{Cu} @ \mathrm{C}$ composite.

The chemical states of $\mathrm{TiO}_{2}$, metallic $\mathrm{Cu}$, and $\mathrm{CDs}$ were determined by XPS analysis. As shown in Figure S1, the XPS spectra of $\mathrm{C} 1 \mathrm{~s}, \mathrm{Ti} 2 \mathrm{p}, \mathrm{O} 1 \mathrm{~s}$, and $\mathrm{Cu} 2 \mathrm{p}$ were compared between pure $\mathrm{TiO}_{2}$ and $\mathrm{TiO}_{2}-$ Cu@C. After curve fitting, the C 1s spectrum exhibited three typical peaks at 284.6, 286.3, and 288.3 $\mathrm{eV}$, which are attributed to $\mathrm{C}-\mathrm{C}, \mathrm{C}-\mathrm{O}$ and $\mathrm{O}=\mathrm{C}-\mathrm{O}$ bonds, respectively. $[27,31,32]$ It can be seen that the relative intensity of the characteristic peaks of $C 1$ s increases with the decoration of CDs. Obviously, the relative intensities of the characteristic peaks of Ti $2 p$ (binding energy $=458.6,464.4 \mathrm{eV}$ ) and $\mathrm{O} 1 \mathrm{~s}$ (binding energy $=529.8 \mathrm{eV}$ ) are lower than that of pure $\mathrm{TiO}_{2}$, which suggests successful modification by the carbon dots. Moreover, the XPS spectrum of Cu 2p (Figure S1d) displays two peaks at 932.2 and $951.8 \mathrm{eV}$, which are associated with $\mathrm{Cu} 2 \mathrm{p}_{3 / 2}$ and $\mathrm{Cu} 2 \mathrm{P}_{1 / 2}$ of copper metal, [33-35] which can only be observed on ternary $\mathrm{TiO}_{2}-\mathrm{Cu} @ \mathrm{C}$ hybrid. The results are consistent with the XRD images, demonstrating the presence of metallic $\mathrm{Cu}$ that is loaded on $\mathrm{TiO}_{2}$. 

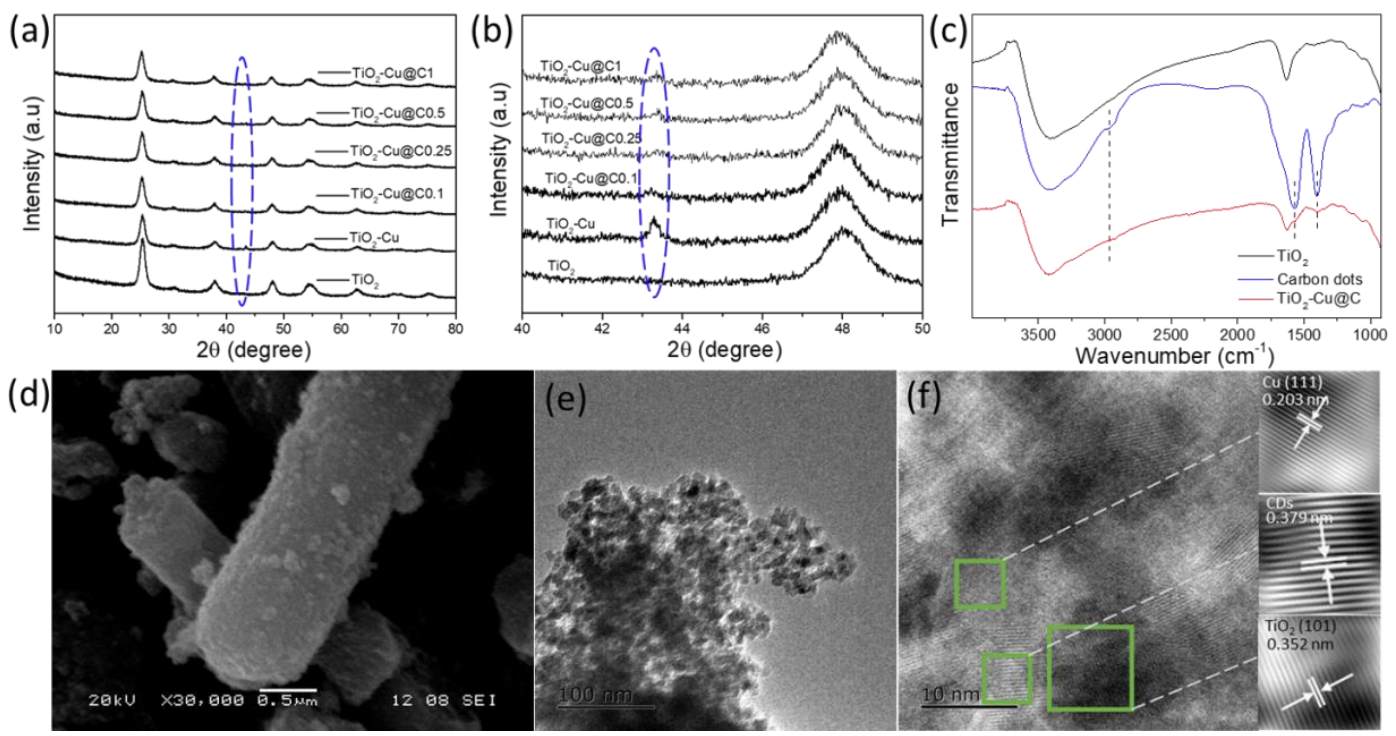

Figure 3. (a) XRD patterns of $\mathrm{TiO}_{2}, \mathrm{TiO}_{2}-\mathrm{Cu}$, and $\mathrm{TiO}_{2}-\mathrm{Cu} @ \mathrm{C}$ hybrid; (b) magnified images that corresponds to

the XRD; (c) FTIR spectra of $\mathrm{TiO}_{2}$, carbon dots, and $\mathrm{TiO}_{2}-\mathrm{Cu} @ \mathrm{C}$; (d) SEM, (e) TEM, and (f) HRTEM images of $\mathrm{TiO}_{2}-$

Cu@C hybrid (insets: inverse fast Fourier transform (IFFT) images).

As shown in Figure S2, porous $\mathrm{TiO}_{2}$ has rod-like structure, where the microrods are about 3-5 $\mu \mathrm{m}$ in length and 0.8-1.1 $\mu \mathrm{m}$ in diameter. It can be seen from the TEM image (Figure S2) that the porous rod structure is composed of nanocrystalline $\mathrm{TiO}_{2}$. Moreover, the high-resolution TEM (HRTEM) images give an understanding of the atomic arrangement on the surfaces of prepared nanoparticles. The lattice fringes with distances of $0.354 \mathrm{~nm}$ are well assigned to $\mathrm{TiO}_{2}$ in the HRTEM image (Figure S2). The XRD pattern of amorphous carbon dots is consistent with those reported in the literature [36], as shown in Figure S3a. The images (Figure 3d-e) of $\mathrm{TiO}_{2}-\mathrm{Cu} @ \mathrm{C}$ displayed a similar rod-like porous structure, and it was composed of aggregated nanoparticles. The CDs could not be distinguished because of their small nanosize (Figure S3b) and closeness to the nanoparticles of $\mathrm{TiO}_{2}$. In the $\mathrm{HRTEM}$ image of $\mathrm{TiO}_{2}-\mathrm{Cu} @ \mathrm{C}$ in Figure 3f, the lattice fringes with spacing of $0.352 \mathrm{~nm}$ are in accordance with the anatase $\mathrm{TiO}_{2}(101)$ interplanar spacing, while the $0.203 \mathrm{~nm}$ fringes agree with the (111) planes of metallic $\mathrm{Cu}$. The results indicate that ternary $\mathrm{TiO}_{2}-\mathrm{Cu} @ \mathrm{C}$ hybrid can be formed via the electrostatic assembly method. 
Element mapping was performed to further confirm the composition of the $\mathrm{TiO}_{2}-\mathrm{Cu} @ \mathrm{C} 0.5$ hybrid.

Figure $\mathbf{S 4}$ displays the area where the elemental mapping performed and the distribution of elements in the $\mathrm{TiO}_{2}$-Cu@C0.5 hybrid with energy-dispersive X-ray (EDX) elemental mapping. The four different colors represent the distribution of $\mathrm{O}, \mathrm{Cu}, \mathrm{C}$ and $\mathrm{Ti}$. The existence of the four elements in the sample is in agreement with the proposed $\mathrm{TiO}_{2}-\mathrm{Cu} @ \mathrm{C} 0.5$ hybrid. As shown in Figure S4, it was clearly observed that $\mathrm{Ti}, \mathrm{O}, \mathrm{Cu}$ and $\mathrm{C}$ elements were evenly distributed on $\mathrm{TiO}_{2}$, which indicated the $\mathrm{TiO}_{2}-\mathrm{Cu} @ \mathrm{C}$ hybrid was successfully synthesized by this method. Moreover, the weight percentage of the elements in the $\mathrm{TiO}_{2}-\mathrm{Cu} @ \mathrm{C} 0.5$ was roughly estimated through selecting two different microrods in the SEM image depicted in Figure S5. The corresponding data were listed in Table S1 and Table S2, and it was found that the weight percentage of carbon dot in the $\mathrm{TiO}_{2}-\mathrm{Cu} @ \mathrm{C} 0.5$ is about $17 \%$. A comparison of ultraviolet-visible diffuse reflectance spectra of $\mathrm{TiO}_{2}, \mathrm{TiO}_{2}-\mathrm{Cu}, \mathrm{TiO}_{2}-\mathrm{C}$, and $\mathrm{TiO}_{2}-\mathrm{Cu} @ \mathrm{C}$ is presented in Figure S6. Compared with pure $\mathrm{TiO}_{2}$, the absorption edge of $\mathrm{TiO}_{2}-\mathrm{Cu}$ has a red shift, which means that the loading with metallic $\mathrm{Cu}$ will enhance light absorption. After further modification by the CDs, a certain enhancement in the absorption is observed in the range of $550-750 \mathrm{~nm}$ on $\mathrm{TiO}_{2}-\mathrm{Cu} @ \mathrm{C}$. This could explain the successful preparation of $\mathrm{TiO}_{2}-\mathrm{Cu} @ \mathrm{C}$ composite through modification by the metallic Cu particles and $\mathrm{CDs}$ decorated on the $\mathrm{TiO}_{2}$ mesoporous microrods.

Water splitting technology driven by solar energy is a promising clean hydrogen production technology. Consequently, the photocatalytic properties of $\mathrm{TiO}_{2}-\mathrm{Cu} @ \mathrm{C}$ nanocomposites were studied under UV-vis light irradiation with methanol (20 vol\%) aqueous solution as the hole sacrificial agent. Figure 4a shows the photocatalytic activity of $\mathrm{TiO}_{2}-\mathrm{Cu} @ \mathrm{C}$ hybrids and the control samples for hydrogen production. There is no obvious $\mathrm{H}_{2}$ generation on $\mathrm{TiO}_{2}$ and binary $\mathrm{TiO}_{2}-\mathrm{C}$. This is probably due to the fact that the carbon dots only serve as electronic mediators rather than active sites. When 
photocatalytic reaction was carried out on binary $\mathrm{TiO}_{2}-\mathrm{Cu}$, the evolution rate of $\mathrm{H}_{2}$ was enhanced sharply to $2462 \mu \mathrm{mol} \mathrm{g}{ }^{-1} \mathrm{~h}^{-1}$, which means that metallic Cu acts as a cocatalyst with benefits for the photocatalytic activity. Furthermore, the activity of $\mathrm{TiO}_{2}-\mathrm{Cu}$ increased by 1.6 times to $3911 \mu \mathrm{mol} \mathrm{g}^{-1} \mathrm{~h}^{-1}$ when the optimum amount of $\mathrm{CDs}$ was used to form $\mathrm{TiO}_{2}-\mathrm{Cu} @ \mathrm{C} 0.5$ ternary composite. Compared with other reported catalysts, $\mathrm{TiO}_{2}-\mathrm{Cu} @ \mathrm{C} 0.5$ hybrid has better hydrogen evolution activity as shown in Table 1. The high photoactivity is attributed to the synergistic effects of the metallic $\mathrm{Cu}$ and carbon dots in $\mathrm{TiO}_{2}-\mathrm{Cu} @ \mathrm{C}$, which greatly improves the separation of photogenerated electrons and holes. At the same time, it was found that the hydrogen evolution activity of ternary $\mathrm{TiO}_{2}-\mathrm{Cu} @ \mathrm{C}$ was lower than that of binary $\mathrm{TiO}_{2}-\mathrm{Cu}$ composite when the $\mathrm{CD}$ s content was lower or higher than the optimum loading amount. We speculate that when the loading of CDS is lower than the optimum amount, because the good conductivity of $\mathrm{CDs}$ and metallic $\mathrm{Cu}, \mathrm{CDs}$ near metallic $\mathrm{Cu}$ but not in contact will divert part of the photogenerated electrons from $\mathrm{TiO}_{2}$, which makes the catalytic activity of $\mathrm{TiO}_{2}$-Cu slightly higher than that of $\mathrm{TiO}_{2}-\mathrm{Cu} @ \mathrm{C}_{\mathrm{x}}$; When the loading of $\mathrm{CDs}$ is higher than the optimum amount, excessive CDs will cover the active sits of metallic Cu cocatalyst, thus reducing the catalytic activity. The apparent quantum efficiency ( $\mathrm{AQE}$ ) of ternary $\mathrm{TiO}_{2}-\mathrm{Cu} @ \mathrm{C} 0.5$ was measured using a $365 \mathrm{~nm}( \pm 2 \mathrm{~nm})$ band-pass filter $\left(12.8 \mathrm{~mW} / \mathrm{cm}^{2}\right)$, and the AQE value was calculated to be $4.64 \%$ according to the previously reported work [37-39]. More importantly, $\mathrm{TiO}_{2}-\mathrm{Cu} @ \mathrm{C}$ exhibits high photocatalytic stability. As depicted in Figure $\mathbf{4 b}$, the photocatalytic hydrogen evolution rate did not decrease detectably after four cycles, which indicates that $\mathrm{TiO}_{2}-\mathrm{Cu} @ \mathrm{C}$ photocatalyst has good stability and reusability. 

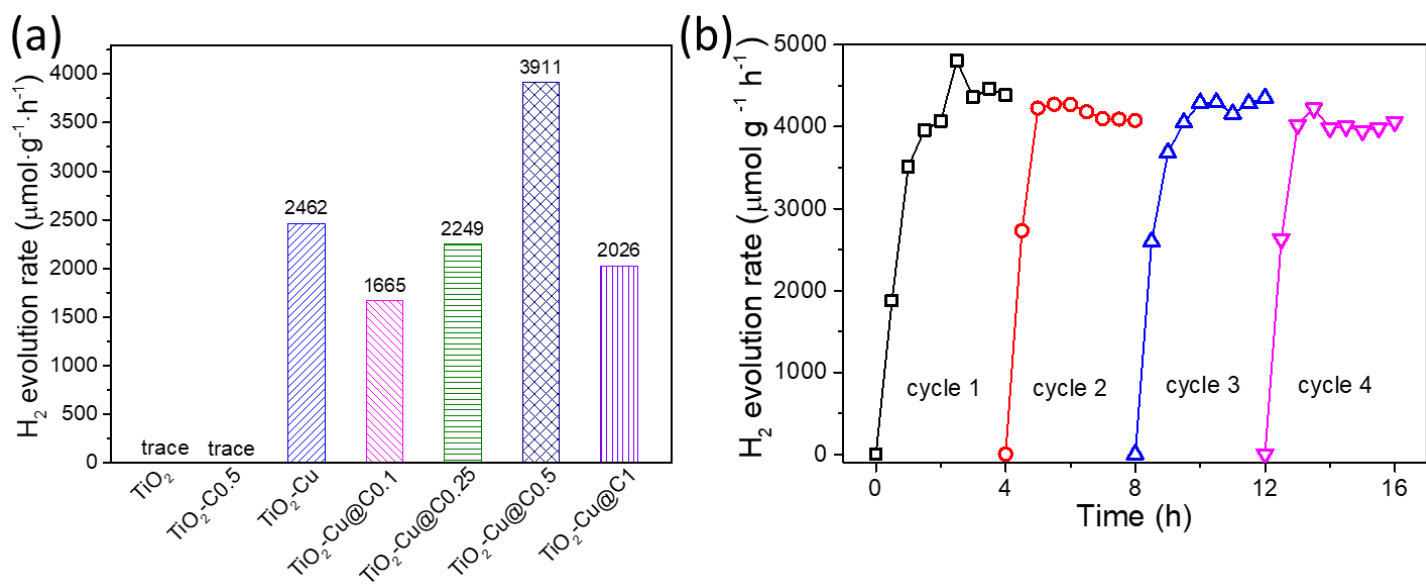

Figure 4. (a) Hydrogen production activity of different photocatalysts; (b) photostability for the $\mathrm{H}_{2}$ production of $\mathrm{TiO}_{2}$-Cu@C0.5_under UV-vis light.

Table 1. Photocatalytic performance comparison for $\mathrm{H}_{2}$ evolution with other reports

\begin{tabular}{|c|c|c|c|}
\hline Materials & $\begin{array}{l}\text { Amount of catalyst } \\
\text { (g) }\end{array}$ & $\begin{array}{c}\mathrm{H}_{2} \text { evolution rate }(\mu \mathrm{mol} \\
\left.\mathrm{g}^{-1} \mathrm{~h}^{-1}\right)\end{array}$ & Ref. \\
\hline $\mathrm{TiO}_{2}$-CQDs & 0.05 & 196 & [40] \\
\hline $\mathrm{g}-\mathrm{C}_{3} \mathrm{~N}_{4}-\mathrm{CQDs}-\mathrm{Pt}$ & 0.05 & 3538 & [41] \\
\hline $\mathrm{TiO}_{2}$-CQDs & 0.02 & 395 & [42] \\
\hline $\mathrm{g}-\mathrm{C}_{3} \mathrm{~N}_{4}-\mathrm{CQDs}-\mathrm{MoS}_{2}$ & 0.05 & 212.4 & [43] \\
\hline TiO_-Cu@c & 0.025 & 3911 & This work \\
\hline
\end{tabular}

To better understand the photocatalytic activity of $\mathrm{TiO}_{2}-\mathrm{Cu} @ \mathrm{C}$, the specific surface and pore size distribution were studied (Figure S7). Table S3 shows there are no obvious differences among the samples in their BET surface areas and pore-sizes, which means that the specific surface area has no effect towards the improvement of photocatalytic activity. Photoelectrochemical tests were carried out to study the performance of the composite catalyst, as shown in Figure 5a. As expected, $\mathrm{TiO}_{2}-\mathrm{Cu} @ \mathrm{C}$ 
exhibits the highest photocurrent intensity compared with $\mathrm{TiO}_{2}, \mathrm{TiO}_{2} @ \mathrm{C}$, and $\mathrm{TiO}_{2}-\mathrm{Cu}$ due to the dualelectron transfer path in the ternary system. Interestingly, sole metallic Cu or carbon dots can greatly improve the charge separation efficiency, which is ascribed to their excellent conductivity. Moreover, electrochemical impedance spectroscopy (EIS) was used to investigate the separation and transfer of photogenerated electron and holes of samples. [44] EIS Nyquist plots of Figure $\mathbf{5 b}$ depicted that ternary $\mathrm{TiO}_{2}-\mathrm{Cu} @ \mathrm{C} 0.5$ hydrid shows the fastest interfacial charge transfer characteristics compared with pure $\mathrm{TiO}_{2}, \mathrm{TiO}_{2}-\mathrm{Cu}, \mathrm{TiO}_{2}-\mathrm{C}$. Furthermore, binary $\mathrm{TiO}_{2}-\mathrm{Cu}$ and $\mathrm{TiO}_{2}-\mathrm{C}$ composites exhibited smaller arc compared with pure $\mathrm{TiO}_{2}$, which indicates that metallic $\mathrm{Cu}$ and carbon dots are helpful to inhibit photogenerated electron-hole recombination, which is also consistent with the corresponding photocurrent results.
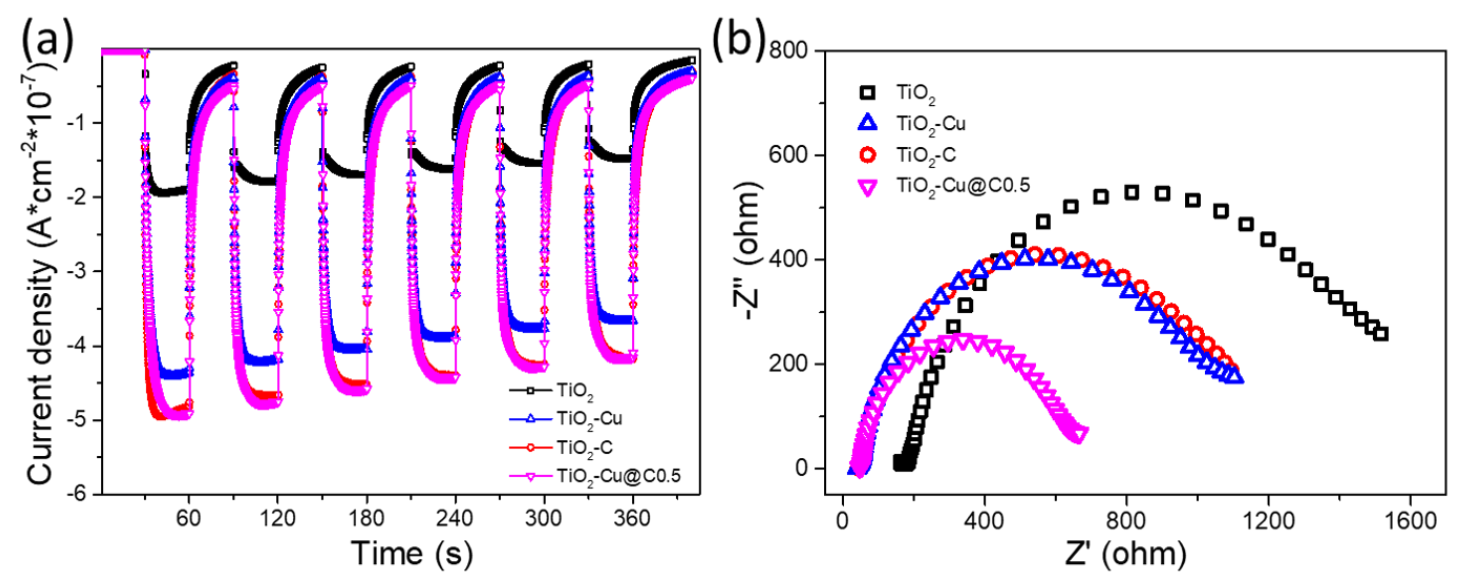

Figure 5 (a) Photocurrent response and (b) Electrochemical impedance spectra (EIS) of $\mathrm{TiO}_{2}, \mathrm{TiO}_{2}-\mathrm{Cu}, \mathrm{TiO}_{2}-\mathrm{C}$, and $\mathrm{TiO}_{2}-\mathrm{Cu} @ \mathrm{C0} .5$.

In addition, the electron transfer of $\mathrm{TiO}_{2}$ in both the binary and ternary composites was investigated by using photoluminescence $(\mathrm{PL})$, as shown in Figure S8. The $\mathrm{PL}$ intensity of $\mathrm{TiO}_{2}$ in both binary and ternary systems is decreased. The marked decline of the PL signals indicates a significant separation of photogenerated carriers, resulting from the efficient electron transfer from the $\mathrm{TiO}_{2}$ to carbon dots and metallic $\mathrm{Cu}$. In order to further understand the charge carrier dynamics, time-resolved 
photoluminescence decay transient spectroscopy was applied to evaluate the charge transfer paths of $\mathrm{TiO}_{2}-\mathrm{Cu} @ \mathrm{C}$, and the normalized decay plots are shown in Figure 6a. The peak attenuation of photoluminescence was fitted to calculate the amplitude and lifetime, as depicted in Figure $\mathbf{6 b}$ and Figure S9 (for detailed calculations see Section S1). The estimated average lifetime of the $\mathrm{TiO}_{2}-\mathrm{C}\left(\tau_{\text {Ave }}\right.$ $=2.95 \mathrm{~ns})$ is shorter than that of pure $\mathrm{TiO}_{2}\left(\tau_{\text {Ave }}=4.03 \mathrm{~ns}\right)$, implying the emergence of a non-radiative pathway from the electronic interactions between $\mathrm{TiO}_{2}$ and the carbon dots. $[45,46]$ In addition, the emission lifetime of $\mathrm{TiO}_{2}-\mathrm{Cu}\left(\tau_{\text {Ave }}=5.24 \mathrm{~ns}\right)$ is obviously increased when compared with pure $\mathrm{TiO}_{2}$. The results show that metallic $\mathrm{Cu}$ deposition on $\mathrm{TiO}_{2}$ can effectively inhibit charge recombination and prolong carrier lifetime. [47] The results for the ternary $\mathrm{TiO}_{2}-\mathrm{Cu} @ \mathrm{C}$ hybrid indicate a longer fluorescence lifetime ( $\tau_{\text {Ave }}=5.27 \mathrm{~ns}$ ). It was speculated that there may be two electron transfer pathways that contribute to the hydrogen production in the photocatalytic process for ternary $\mathrm{TiO}_{2}-$ Cu@C.

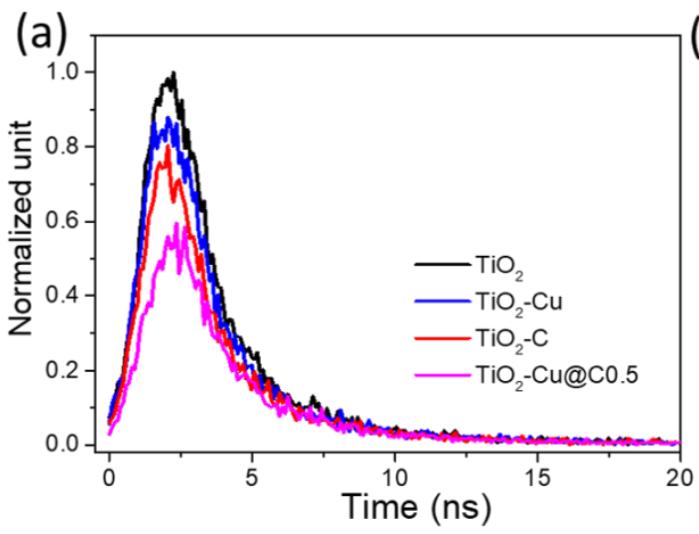

(b)

\begin{tabular}{cccccc}
\hline sample & $\tau_{1}(\mathrm{~ns})$ & $\tau_{2}(\mathrm{~ns})$ & $\mathrm{A}_{1}(\%)$ & $\mathrm{A}_{2}(\%)$ & Ave. $\tau(\mathrm{ns})$ \\
\hline $\mathrm{TiO}_{2}$ & 1.57 & 5.57 & 68.87 & 31.13 & 4.03 \\
$\mathrm{TiO}_{2}-\mathrm{C}$ & 1.23 & 3.46 & 45.72 & 54.28 & 2.95 \\
$\mathrm{TiO}_{2}-\mathrm{Cu}$ & 1.47 & 6.57 & 61.40 & 38.60 & 5.24 \\
$\begin{array}{c}\mathrm{TiO}_{2-} \\
\mathrm{Cu} @ \mathrm{C} 0.5\end{array}$ & 1.72 & 6.79 & 62.63 & 37.37 & 5.27 \\
\hline
\end{tabular}

Figure 6. (a) time-resolved photoluminescence decay transients and (b) the lifetimes calculated by the exponential decay function of $\mathrm{TiO}_{2}, \mathrm{TiO}_{2}-\mathrm{Cu}, \mathrm{TiO}_{2}-\mathrm{C}$, and $\mathrm{TiO}_{2}-\mathrm{Cu} @ \mathrm{C} 0.5$.

Based on the above results and analysis, the details of the photocatalytic process of ternary $\mathrm{TiO}_{2}$ Cu@C heterostructure could be determined. As shown in Figure 7, when the photocatalytic reaction occurs, the photogenerated electrons from the valence band (VB) of $\mathrm{TiO}_{2}$ move to its conduction band 
(CB), leaving the holes in the VB. Subsequently, photogenerated electrons are transferred at the $\mathrm{TiO}_{2}-$ $\mathrm{Cu}, \mathrm{TiO}_{2}-\mathrm{C}$, and carbon- $\mathrm{Cu}$ interfaces due to the matching of work functions and intimate contact through two electron transfer paths: (1) direct transfer of the photogenerated electrons from $\mathrm{TiO}_{2}$ to the metallic $\mathrm{Cu}$ or carbon dots; and (2) injection of the photogenerated electrons from $\mathrm{TiO}_{2}$ to the carbon dots to the metallic $\mathrm{Cu}$. Based on the comprehensive photocatalytic and photoelectric tests, it is proposed that carbon dots can only be used as a medium for electrons, but not as an active site to reduce water to hydrogen. Thus, it was concluded that the further increase in the activity of ternary $\mathrm{TiO}_{2}-\mathrm{Cu} @ \mathrm{C}$ should be attributed to the transfer of electrons excited on $\mathrm{TiO}_{2}$ to carbon dots first and then to metallic Cu.

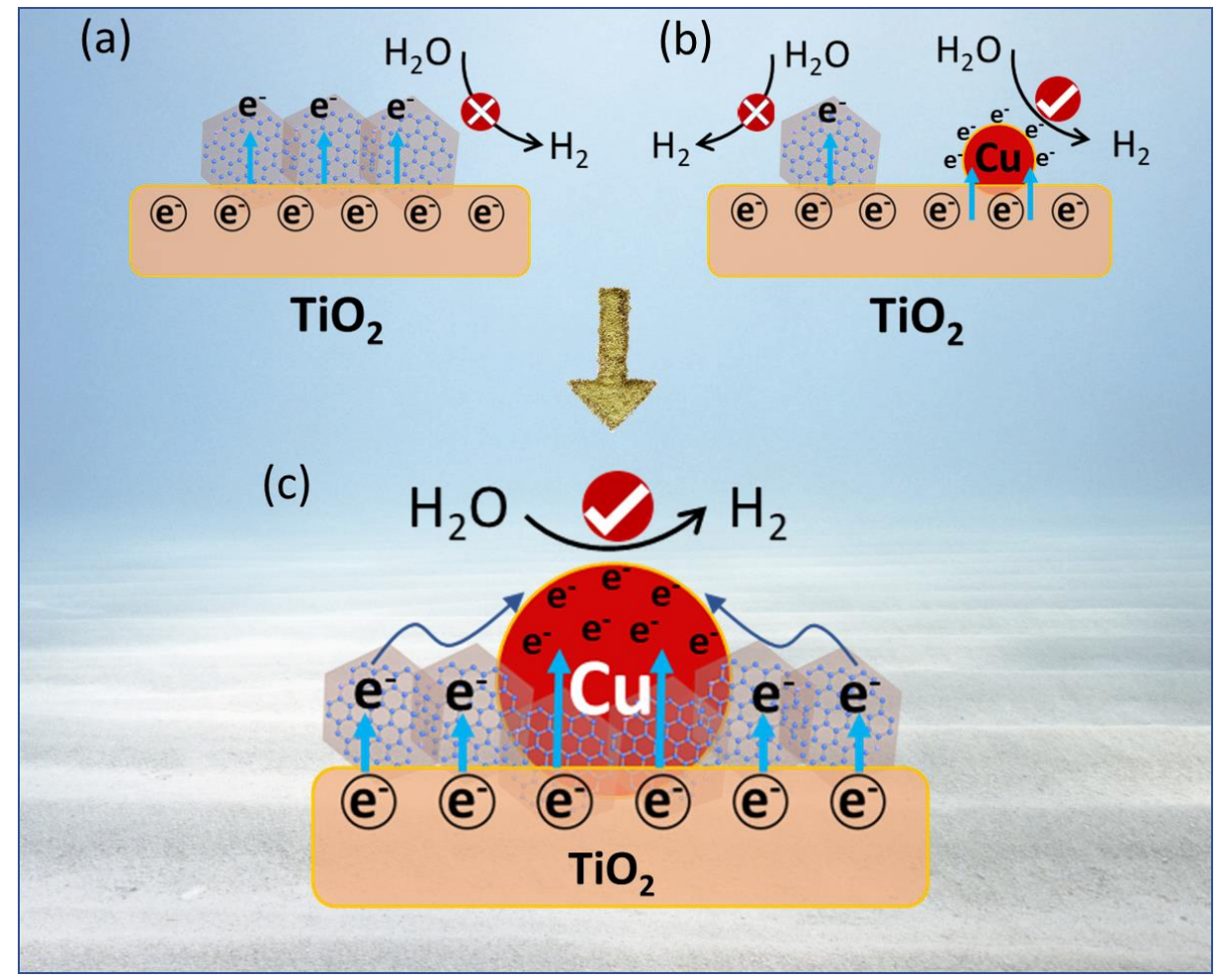

Figure 7. Schematic illustration of the transport and separation of photogenerated electrons in (a) $\mathrm{TiO}_{2} @ \mathrm{C}$, (b) $\mathrm{TiO}_{2}-\mathrm{Cu}$, and (c) $\mathrm{TiO}_{2}-\mathrm{Cu} @ \mathrm{C}$ composites.

\section{Conclusions}


In conclusion, we have developed a simple and feasible electrostatic self-assembly method to control the synthesis of ternary $\mathrm{TiO}_{2}-\mathrm{Cu} @ \mathrm{C}$ composites without noble metal catalysts. The composites exhibited highly efficient photocatalytic activity towards water decomposition into hydrogen. The optimum TiO2-Cu@C0.5 hybrid achieved a high hydrogen evolution rate of $3911 \mu \mathrm{mol} \mathrm{g}{ }^{-1} \mathrm{~h}^{-1}$, which is many times higher than that of pure $\mathrm{TiO}_{2}$ and 1.6 times higher than that of $\mathrm{TiO}_{2}-\mathrm{Cu}$. We found that the CDs could not be used as catalysis active sites, but could be used as an electronic mediator, so the enhancement of activity was attributed to effective charge transfer. The formation of the interface between $\mathrm{C}-\mathrm{Cu}$ and $\mathrm{C}-\mathrm{TiO}_{2}$ provides another route for electron transfer, which enables photogenerated electrons on $\mathrm{TiO}_{2}$ to be transferred to metallic $\mathrm{Cu}$ through $\mathrm{CDs}$, not just by direct transfer to metallic $\mathrm{Cu}$. This rational design could further broaden the preparation of ternary nanocomposites for photocatalysis.

\section{Contributions}

GC and JX designed the project, organized the entire research, and revised the manuscript. JZ prepared the materials, did the photocatalysis, photocurrent, and EIS measurements. MZ, YY and WL were involved in interpretation of the result and commented on the manuscript. All authors reviewed the manuscript.

\section{Acknowledgements}

This work was supported by the National Natural Science Foundation of China (21501137) and Hubei Provincial Natural Science Foundation (2018CFB680). Dr. W. J. Li thanks the Australian Research Council for funding through Discovery Early Career Researcher Award (DECRA, No. DE180101478). The authors also thank Dr. Tania Silver for critical reading of the manuscript. 


\section{Conflict of Interest}

The authors report no conflict of interest.

\section{References}

[1] X. Chen, L. Liu, P.Y. Yu, S.S. Mao, Increasing solar absorption for photocatalysis with black hydrogenated titanium dioxide nanocrystals, Science, 331 (2011) 746-750.

[2] A. Naldoni, M. Altomare, G. Zoppellaro, N. Liu, Š. Kment, R. Zbořil, P. Schmuki, Photocatalysis with reduced $\mathrm{TiO}_{2}$ : From black $\mathrm{TiO}_{2}$ to cocatalyst-free hydrogen production, ACS Catalysis, 9 (2019) 345-364. [3] D. Wang, P. Kanhere, M. Li, Q. Tay, Y. Tang, Y. Huang, T.C. Sum, N. Mathews, T. Sritharan, Z. Chen, Improving photocatalytic $\mathrm{H}_{2}$ evolution of $\mathrm{TiO}_{2}$ via formation of $\{001\}-\{010\}$ quasi-heterojunctions, The Journal of Physical Chemistry C, 117 (2013) 22894-22902.

[4] W. Zhou, W. Li, J.Q. Wang, Y. Qu, Y. Yang, Y. Xie, K.F. Zhang, L. Wang, H.G. Fu, D.Y. Zhao, Ordered mesoporous black $\mathrm{TiO}_{2}$ as highly efficient hydrogen evolution photocatalyst, Journal of the American Chemical Society, 136 (2014) 9280-9283.

[5] M. Pirhashemi, A. Habibi-Yangjeh, S. Rahim Pouran, Review on the criteria anticipated for the fabrication of highly efficient ZnO-based visible-light-driven photocatalysts, Journal of Industrial and Engineering Chemistry, 62 (2018) 1-25.

[6] M. Shekofteh-Gohari, A. Habibi-Yangjeh, M. Abitorabi, A. Rouhi, Magnetically separable nanocomposites based on $\mathrm{ZnO}$ and their applications in photocatalytic processes: A review, Critical Reviews In Environmental Science And Technology, 48 (2018) 806-857.

[7] Y. Lu, X. Cheng, G. Tian, H. Zhao, L. He, J. Hu, S.-M. Wu, Y. Dong, G.-G. Chang, S. Lenaerts, S. Siffert, G. Van Tendeloo, Z.-F. Li, L.-L. Xu, X.-Y. Yang, B.-L. Su, Hierarchical CdS/m-TiO2/G ternary photocatalyst 
for highly active visible light-induced hydrogen production from water splitting with high stability, Nano Energy, 47 (2018) 8-17.

[8] B. Wu, D. Liu, S. Mubeen, T.T. Chuong, M. Moskovits, G.D. Stucky, Anisotropic growth of $\mathrm{TiO}_{2}$ onto gold nanorods for plasmon-enhanced hydrogen production from water reduction, Journal of the American Chemical Society, 138 (2016) 1114-1117.

[9] J. Zhang, Z. Yu, Z. Gao, H. Ge, S. Zhao, C. Chen, S. Chen, X. Tong, M. Wang, Z. Zheng, Y. Qin, Porous $\mathrm{TiO}_{2}$ nanotubes with spatially separated platinum and $\mathrm{CoO}_{x}$ cocatalysts produced by atomic layer deposition for photocatalytic hydrogen production, Angewandte Chemie International Edition, 56 (2017) 816-820.

[10] W. Zhou, Z. Yin, Y. Du, X. Huang, Z. Zeng, Z. Fan, H. Liu, J. Wang, H. Zhang, Synthesis of few-layer $\mathrm{MoS}_{2}$ nanosheet-coated $\mathrm{TiO}_{2}$ nanobelt heterostructures for enhanced photocatalytic activities, Small, 9 (2013) 140-147.

[11] Q.J. Xiang, J.G. Yu, M. Jaroniec, Synergetic effect of $\mathrm{MoS}_{2}$ and graphene as cocatalysts for enhanced photocatalytic $\mathrm{H}_{2}$ production activity of $\mathrm{TiO}_{2}$ nanoparticles, Journal of the American Chemical Society, 134 (2012) 6575-6578.

[12] K. Iwashina, A. Iwase, Y.H. Ng, R. Amal, A. Kudo, Z-schematic water splitting into $\mathrm{H}_{2}$ and $\mathrm{O}_{2}$ using metal sulfide as a hydrogen-evolving photocatalyst and reduced graphene oxide as a solid-state electron mediator, Journal of the American Chemical Society, 137 (2015) 604-607.

[13] S. Xiao, P. Liu, W. Zhu, G. Li, D. Zhang, H. Li, Copper nanowires: A substitute for noble metals to enhance photocatalytic $\mathrm{H}_{2}$ generation, Nano Letters, 15 (2015) 4853-4858. 
[14] J.-X. Feng, J.-Q. Wu, Y. Tong, G.-R. Li, Efficient hydrogen evolution on Cu nanodots-decorated $\mathrm{Ni}_{3} \mathrm{~S}_{2}$ nanotubes by optimizing atomic hydrogen adsorption and desorption, Journal of the American Chemical Society, 140 (2017) 610-617.

[15] N.L. Reddy, S. Kumar, V. Krishnan, M. Sathish, M.V. Shankar, Multifunctional Cu/Ag quantum dots on $\mathrm{TiO}_{2}$ nanotubes as highly efficient photocatalysts for enhanced solar hydrogen evolution, Journal of Catalysis, 350 (2017) 226-239.

[16] P. Zhang, T. Song, T. Wang, H. Zeng, Enhancement of hydrogen production of a $\mathrm{Cu}-\mathrm{TiO}_{2}$ nanocomposite photocatalyst combined with broad spectrum absorption sensitizer Erythrosin B, RSC Advances, 7 (2017) 17873-17881.

[17] P. Zhang, T. Wang, H. Zeng, Design of $\mathrm{Cu}-\mathrm{Cu}_{2} \mathrm{O} / \mathrm{g}-\mathrm{C}_{3} \mathrm{~N}_{4}$ nanocomponent photocatalysts for hydrogen evolution under visible light irradiation using water-soluble Erythrosin B dye sensitization, Applied Surface Science, 391 (2017) 404-414.

[18] X. Xu, F. Luo, W. Tang, J. Hu, H. Zeng, Y. Zhou, Enriching hot electrons via NIR-photon-excited plasmon in WS $@$ @Cu hybrids for full-spectrum solar hydrogen evolution, Advanced Functional Materials, 28 (2018) 1804055.

[19] J. Greeley, T.F. Jaramillo, J. Bonde, I. Chorkendorff, J.K. Nørskov, Computational high-throughput screening of electrocatalytic materials for hydrogen evolution, Nature Materials, 5 (2006) 909-913.

[20] J.-X. Feng, H. Xu, Y.-T. Dong, X.-F. Lu, Y.-X. Tong, G.-R. Li, Efficient hydrogen evolution electrocatalysis using cobalt nanotubes decorated with titanium dioxide nanodots, Angewandte Chemie International Edition, 56 (2017) 2960-2964. 
[21] J.-X. Feng, S.-Y. Tong, Y.-X. Tong, G.-R. Li, Pt-like hydrogen evolution electrocatalysis on PANI/CoP hybrid nanowires by weakening the shackles of hydrogen ions on the surfaces of catalysts, Journal of the American Chemical Society, 140 (2018) 5118-5126.

[22] I. Pastoriza-Santos, A. Sánchez-Iglesias, B. Rodríguez-González, L.M. Liz-Marzán, Aerobic synthesis of Cu nanoplates with intense plasmon resonances, Small, 5 (2009) 440-443.

[23] M. Jin, G. He, H. Zhang, J. Zeng, Z. Xie, Y. Xia, Shape-controlled synthesis of copper nanocrystals in an aqueous solution with glucose as a reducing agent and hexadecylamine as a capping agent, Angewandte Chemie International Edition, 50 (2011) 10560-10564.

[24] P. Zhang, G. Zeng, T. Song, S. Huang, T. Wang, H. Zeng, Design of plasmonic CuCo bimetal as a nonsemiconductor photocatalyst for synchronized hydrogen evolution and storage, Applied Catalysis B: Environmental, 242 (2019) 389-396.

[25] N. Lu, Z. Zhang, Y. Wang, B. Liu, L. Guo, L. Wang, J. Huang, K. Liu, B. Dong, Direct evidence of IRdriven hot electron transfer in metal-free plasmonic $\mathrm{W}_{18} \mathrm{O}_{49} /$ carbon heterostructures for enhanced catalytic $\mathrm{H}_{2}$ production, Applied Catalysis B: Environmental, 233 (2018) 19-25.

[26] P. Zhang, T. Song, T. Wang, H. Zeng, In-situ synthesis of Cu nanoparticles hybridized with carbon quantum dots as a broad spectrum photocatalyst for improvement of photocatalytic $\mathrm{H}_{2}$ evolution, Applied Catalysis B: Environmental, 206 (2017) 328-335.

[27] H. Yu, Y. Zhao, C. Zhou, L. Shang, Y. Peng, Y. Cao, L.-Z. Wu, C.-H. Tung, T. Zhang, Carbon quantum dots $/ \mathrm{TiO}_{2}$ composites for efficient photocatalytic hydrogen evolution, Journal of Materials Chemistry $\mathrm{A}$, 2 (2014) 3344-3351.

[28] Y. Zhang, M. Xu, H. Li, H. Ge, Z. Bian, The enhanced photoreduction of $\mathrm{Cr}(\mathrm{VI})$ to $\mathrm{Cr}(\mathrm{III})$ using carbon dots coupled $\mathrm{TiO}_{2}$ mesocrystals, Applied Catalysis B: Environmental, 226 (2018) 213-219. 
[29] J. Wang, L. Tang, G. Zeng, Y. Deng, H. Dong, Y. Liu, L. Wang, B. Peng, C. Zhang, F. Chen, OD/2D interface engineering of carbon quantum dots modified $\mathrm{Bi}_{2} \mathrm{WO}_{6}$ ultrathin nanosheets with enhanced photoactivity for full spectrum light utilization and mechanism insight, Applied Catalysis B: Environmental, 222 (2018) 115-123.

[30] S. Cao, J. Yu, Carbon-based $\mathrm{H}_{2}$-production photocatalytic materials, Journal of Photochemistry and Photobiology C: Photochemistry Reviews, 27 (2016) 72-99.

[31] J. Di, J. Xia, M. Ji, B. Wang, S. Yin, Q. Zhang, Z. Chen, H. Li, Carbon quantum dots modified BiOCl ultrathin nanosheets with enhanced molecular oxygen activation ability for broad spectrum photocatalytic properties and mechanism insight, ACS Applied Materials \& Interfaces, 7 (2015) 2011120123.

[32] X.-H. Jiang, L.-C. Wang, F. Yu, Y.-C. Nie, Q.-J. Xing, X. Liu, Y. Pei, J.-P. Zou, W.-L. Dai, Photodegradation of organic pollutants coupled with simultaneous photocatalytic evolution of hydrogen using quantum-dot-modified g- $\mathrm{C}_{3} \mathrm{~N}_{4}$ catalysts under visible-light irradiation, ACS Sustainable Chemistry \& Engineering, 6 (2018) 12695-12705.

[33] H. Yang, Y. Chen, X. Cui, G. Wang, Y. Cen, T. Deng, W. Yan, J. Gao, S. Zhu, U. Olsbye, J. Wang, W. Fan, A highly stable copper-based catalyst for clarifying the catalytic roles of $\mathrm{Cu}^{0}$ and $\mathrm{Cu}^{+}$species in methanol dehydrogenation, Angewandte Chemie International Edition, 57 (2018) 1836-1840.

[34] T. Zhang, J. Low, X. Huang, J.F. Al-Sharab, J. Yu, T. Asefa, Copper-Decorated Microsized Nanoporous Titanium Dioxide Photocatalysts for Carbon Dioxide Reduction by Water, ChemCatChem, 9 (2017) 3054 3062. 
[35] Y.-e. Shi, S. Luo, X. Ji, F. Liu, X. Chen, Y. Huang, L. Dong, L. Wang, Synthesis of ultra - stable copper nanoclusters and their potential application as a reversible thermometer, Dalton Transactions, 46 (2017) 14251-14255.

[36] B.C.M. Martindale, G.A.M. Hutton, C.A. Caputo, S. Prantl, R. Godin, J.R. Durrant, E. Reisner, Enhancing light absorption and charge transfer efficiency in carbon dots through graphitization and core nitrogen doping, Angewandte Chemie International Edition, 56 (2017) 6459-6463.

[37] P. Zhang, T. Song, T. Wang, H. Zeng, Fabrication of a non-semiconductor photocatalytic system using dendrite-like plasmonic CuNi bimetal combined with a reduced graphene oxide nanosheet for near-infrared photocatalytic $\mathrm{H}_{2}$ evolution, Journal of Materials Chemistry A, 5 (2017) 22772-22781.

[38] P. Zhang, G. Zeng, T. Song, S. Huang, T. Wang, H. Zeng, Synthesis of a plasmonic CuNi bimetal modified with carbon quantum dots as a non-semiconductor-driven photocatalyst for effective water splitting, Journal of Catalysis, 369 (2019) 267-275.

[39] P. Wang, Y. Lu, X. Wang, H. Yu, Co-modification of amorphous-Ti(IV) hole cocatalyst and Ni(OH) 2 electron cocatalyst for enhanced photocatalytic $\mathrm{H}_{2}$-production performance of $\mathrm{TiO}_{2}$, Applied Surface Science, 391 (2017) 259-266.

[40] R. Shi, Z. Li, H. Yu, L. Shang, C. Zhou, G.I.N. Waterhouse, L.-Z. Wu, T. Zhang, Effect of nitrogen doping Level on the performance of $\mathrm{N}$-doped carbon quantum dot $/ \mathrm{TiO}_{2}$ composites for photocatalytic hydrogen evolution, ChemSusChem, 10 (2017) 4650-4656.

[41] Y. Wang, X. Liu, J. Liu, B. Han, X. Hu, F. Yang, Z. Xu, Y. Li, S. Jia, Z. Li, Y. Zhao, Carbon quantum dot implanted graphite carbon nitride nanotubes: Excellent charge separation and enhanced photocatalytic hydrogen evolution, Angewandte Chemie International Edition, 57 (2018) 5765-5771. 
[42] Y. Sui, L. Wu, S. Zhong, Q. Liu, Carbon quantum dots $/ \mathrm{TiO}_{2}$ nanosheets with dominant (001) facets for enhanced photocatalytic hydrogen evolution, Applied Surface Science, 480 (2019) 810-816.

[43] Y. Jiao, Q. Huang, J. Wang, Z. He, Z. Li, A novel MoS 2 quantum dots (QDs) decorated Z-scheme g$\mathrm{C}_{3} \mathrm{~N}_{4}$ nanosheet/N-doped carbon dots heterostructure photocatalyst for photocatalytic hydrogen evolution, Applied Catalysis B: Environmental, 247 (2019) 124-132.

[44] Y. Gan, Y. Wei, J. Xiong, G. Cheng, Impact of post-processing modes of precursor on adsorption and photocatalytic capability of mesoporous $\mathrm{TiO}_{2}$ nanocrystallite aggregates towards ciprofloxacin removal, Chemical Engineering Journal, 349 (2018) 1-16.

[45] M.-Y. Ye, Z.-H. Zhao, Z.-F. Hu, L.-Q. Liu, H.-M. Ji, Z.-R. Shen, T.-Y. Ma, OD/2D heterojunctions of vanadate quantum dots/graphitic carbon nitride nanosheets for enhanced vsible-light-driven photocatalysis, Angewandte Chemie International Edition, 56 (2017) 8407-8411.

[46] Y. Wei, G. Cheng, J. Xiong, F. Xu, R. Chen, Positive $\mathrm{Ni}\left(\mathrm{HCO}_{3}\right)_{2}$ as a novel cocatalyst for boosting the photocatalytic hydrogen evolution capability of mesoporous $\mathrm{TiO}_{2}$ nanocrystals, ACS Sustainable Chemistry \& Engineering, 5 (2017) 5027-5038.

[47] J. Ran, G. Gao, F.-T. Li, T.-Y. Ma, A. Du, S.-Z. Qiao, $\mathrm{Ti}_{3} \mathrm{C}_{2}$ MXene co-catalyst on metal sulfide photoabsorbers for enhanced visible-light photocatalytic hydrogen production, Nature Communications, 8 (2017) 13907. 